\title{
Preparation, Crystal Structure, and Physical Properties of a Pyrogallol-bridged Vanadium(III) Complex
}

\author{
Seunghee Lee,a Koji Nakanishi, a Michael Y. Chiang,a Richard B. Frankel,b and Kevos Spartaliane \\ a Department of Chemistry, Columbia University, New York, NY 10027, U.S.A. \\ b Francis Bitter National Magnet Laboratory, Massachusetts Institute of Technology, Cambridge, MA 02139, U.S.A. \\ c Department of Physics, University of Vermont, Burlington, VT 05405, U.S.A.
}

The structure, n.m.r. spectrum, and magnetic properties of the vanadium(mi) dimer $\left[(\operatorname{acac})_{4} \mathrm{~V}_{2}\left\{\mu-\mathrm{OC}_{6} \mathrm{H}_{3}(\mathrm{OH})_{2}\right\}_{2}\right]$ formed from [VO(acac) ${ }_{2}$ ] and an excess of pyrogallol are described.

Vanadium is sequestered and stored as VIII (ref. 1) in certain species of tunicates at a level $10^{6}$ times that present in sea water. ${ }^{2}$ Although this subject has been studied extensively by chemists and biologists, many questions remain. Several years ago, a class of low molecular weight blood pigments, the tunichromes, was characterized as possessing pyrogallol and catechol moieties. ${ }^{3,4}$ E.p.r. ${ }^{4}$ and u.v.-visible absorption spectroscopy ${ }^{5}$ in vitro have shown that tunichrome reduces $V^{V}$ to VIV. Several descriptions of vanadium-catechol complexes have appeared in the literature. The reaction of $\mathrm{VO}(\mathrm{acac})_{2}$ with catechol under basic conditions, by use of the disodium salt of catechol or triethylamine, yields $\left[\mathrm{VIV}^{\mathrm{O}}(3,5-\mathrm{dtbc})_{2}\right]^{2-}$ and $\left[\mathrm{VIV}^{\mathrm{IV}}(3,5 \text {-dtbc })_{3}\right]^{2-}(3,5$-dtbc $=3,5$-di-t-butylcatechol $)$, respectively. ${ }^{6,7}$ In contrast, the product formed in the absence of base displayed an e.p.r. spectrum assignable to a VIIIsemiquinone complex, $\mathrm{V}(3,5-\mathrm{dbsq})_{3},{ }^{8 \mathrm{a}}$ this product is also obtained from the reaction of $\mathrm{V}(\mathrm{CO})_{6}$ with 3,5-di-t-butyl-1,2benzoquinone. ${ }^{8}$ Pyrogallol complexes of vanadium have been identified on the basis of data from potentiometry, ${ }^{9}$ polarography, ${ }^{10}$ and u.v. spectroscopy, ${ }^{11}$ but as yet no $X$-ray crystallographic structure has been reported.

In this paper we report the structure and spectral and magnetic properties of the product of reduction of VIV by pyrogallol, $\uparrow$ the pyrogallol-bridged VIII dimer, [(acac) ${ }_{4} V_{2}\{\mu$ $\left.\left.\mathrm{OC}_{6} \mathrm{H}_{3}(\mathrm{OH})_{2}\right\}_{2}\right]$ (1) (Figure 1). The structure was solved by direct methods and refined to final residuals $R=0.056, R_{\mathrm{w}}=$ $0.075 . \ddagger$ Without the solvent molecule (toluene) the compound has $C_{2}$ symmetry about the $\mathrm{V} \cdots \mathrm{V}$ axis. The $\mathrm{V} \cdots \mathrm{V}$ separation is $3.146 \AA$, which precludes $\mathrm{V}-\mathrm{V}$ bonding. ${ }^{13}$ The magnetic susceptibility, measured from 10 to $300 \mathrm{~K}$, exhibited antiferromagnetically coupled dimer behaviour, first increasing and then decreasing with increasing temperature. The data fit the Hamiltonian (1), ${ }^{14}$ where $S_{1}=S_{2}=1$ for $\mathrm{V}^{3+}$, yielding

$$
\mathbf{H}=-J S_{1} \cdot S_{2}-j\left(S_{1} \cdot S_{2}\right)^{2}
$$

$-J=44.8 \mathrm{~cm}^{-1}$ and $-j=3.7 \mathrm{~cm}^{-1}$. A temperature-

$\uparrow$ The complex $\left[(\mathrm{acac})_{4} \mathrm{~V}_{2}\left(\mu-\mathrm{OC}_{6} \mathrm{H}_{3}(\mathrm{OH})_{2}\right)_{2}\right]$ (1) was prepared as follows. Pyrogallol $(1.70 \mathrm{~g}, 13.5 \mathrm{mmol})$ was dissolved in THF $(50 \mathrm{ml})$. [VO (acac) $\left.)_{2}\right]^{12}(1.03 \mathrm{~g}, 3.9 \mathrm{mmol})$ was added and the mixture was stirred overnight. The solution was evaporated and the residue was treated with hot toluene $(50 \mathrm{ml})$ and filtered. Cooling of the filtrate yielded dark crystals $(0.281 \mathrm{~g}, 24 \%)$, suitable for $X$-ray diffraction. The solution was dark greenish brown (Found: $\mathrm{C}, 55.6 ; \mathrm{H}, 5.7 ; \mathrm{V}$, 12.15. $\mathrm{C}_{32} \mathrm{H}_{38} \mathrm{O}_{14} \mathrm{~V}_{2} \cdot \mathrm{C}_{7} \mathrm{H}_{8}$ requires $\mathrm{C}, 55.7 ; \mathrm{H}, 5.5 ; \mathrm{V}, 12.1 \%$ ).

$\ddagger$ Compound (1): $\mathrm{C}_{32} \mathrm{H}_{38} \mathrm{O}_{14} \mathrm{~V}_{2} \cdot \mathrm{C}_{7} \mathrm{H}_{8} ; M 840.68$; crystal size, $0.30 \times$ $0.40 \times 0.50 \mathrm{~mm}$; monoclinic; space group $C_{c} ; a=14.207(4), b=$ 24.289(4), $c=11.773(2) \AA ; \beta=96.27(2)^{\circ} ; V=4038(1) \AA^{3} ; Z=4$; $D_{\mathrm{c}}=1.38 \mathrm{~g} \mathrm{~cm}^{-3}$. Nicolet $\mathrm{R} 3 \mathrm{~m}$ diffractometer, $\mathrm{Cu}(\lambda 1.54178 \AA \mathrm{A}), 298$ $\mathrm{K} ; \omega$ scan; $\sin \theta / \lambda$ limit $0.59 \AA^{-1}\left(2 \theta_{\max } 130^{\circ}\right) ; 4269$ reflections used; 454 parameters varied; $R=\Sigma\left(\left|F_{\mathrm{o}}\right|-\left|F_{\mathrm{c}}\right|\right) / \Sigma\left|F_{\mathrm{o}}\right|=0.056, R_{\mathrm{w}}=$ $\left[\Sigma w\left(\left|F_{\mathrm{o}}\right|-\left|F_{\mathrm{c}}\right|\right)^{2 / \Sigma w}\left|F_{\mathrm{o}}\right|^{2}\right]^{1 / 2}=0.075, w=1 /\left[\sigma^{2}\left(F_{\mathrm{o}}\right)+0.00145\left(F_{\mathrm{o}}\right)^{2}\right] ;$ absorption coefficient $\mu_{\text {calc }}=46.9 \mathrm{~cm}^{-1}$. Atomic co-ordinates, bond lengths and angles, and thermal parameters have been deposited at the Cambridge Crystallographic Data Centre. See Notice to Authors, Issue No. 1. independent paramagnetic term and a small $(3 \%)$ paramagnetic impurity contribution were also included. Attempts to fit the data by assuming two antiferromagnetically coupled $S=$ $1 / 2$ spins were not successful. The molecular ion $(M+\mathrm{H})$ at 749 (fast atom bombardment mass spectrometry; ethylene glycol matrix), together with magnetic moment data, supports the presence of two VIII atoms in the molecule.

Since electron relaxation of VIII is rapid, complexes of this oxidation state are detectable by n.m.r. The n.m.r. spectrum of the complex (1)§ has been compared with that of $\left[\mathrm{V}(\mathrm{acac})_{3}\right] \cdot{ }^{15-17}$ Whereas the methyl groups of [V(acac $\left.)_{3}\right]$ resonate at $\delta 45,16$ those in the complex (1) resonate at 47.9 and $39.4(1: 1)$; the $10-, 10^{\prime}-, 15-$, and $15^{\prime}$-methyl groups are shielded by the aromatic rings (Figure 1) and exhibit the expected upfield shift to $\delta 39.4$. The 9-, $9^{\prime}-, 14-$, and $14^{\prime}$-methine protons exhibit shifts from $\delta 40.1$ in [ $\mathrm{V}(\mathrm{acac})_{3}$ ] to $\delta 28.7$. As suggested by Eaton, ${ }^{15}$ this arises from an increase in electron density at the methine position attributable to
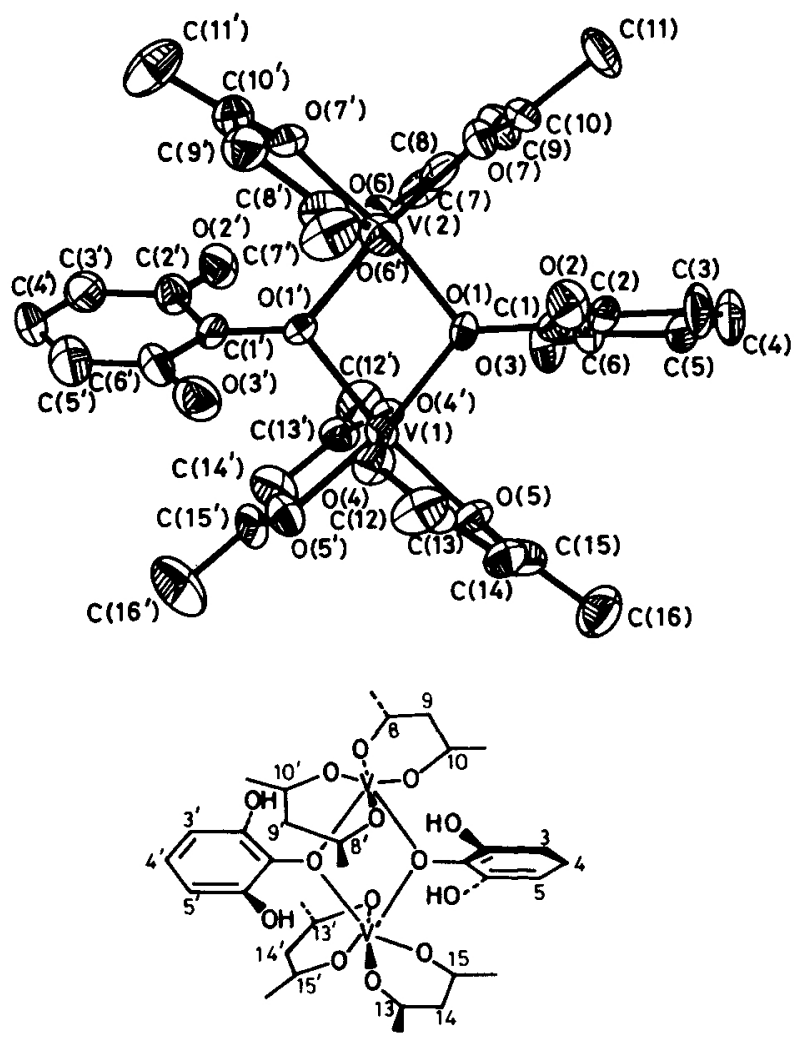

Figure 1. ORTEP structure of the complex (1).

$\S$ 'H N.m.r. $\left(250 \mathrm{MHz} ; \mathrm{CDCl}_{3} ; 20^{\circ} \mathrm{C}\right) \delta 47.9$ (s, 12H), 39.4 (s, 12H), $28.7(\mathrm{~s}, 4 \mathrm{H}), 11.0(\mathrm{br}, \mathrm{s},>4 \mathrm{H})$, and $9.4(\mathrm{~s}, 4 \mathrm{H})$. 
ligand-to-metal $\alpha$-spin transfer, which leaves a $\beta$-spin on the: ligand. The meta-protons at positions $3,3^{\prime}, 5$, and $5^{\prime}$ appeared as a singlet at $\delta 9.4$. Upon deuteriation of the phenolic groups; (broad peaks at $\delta 11.5-10.2$ ), the overlapping singlet at: $\delta 11.0$ integrated for 2 protons ( $\mathrm{H}-4$ and $\left.-4^{\prime}\right)$.

Overnight stirring of [ $\left.\mathrm{VO}(\mathrm{acac})_{2}\right]$ and 2 equiv. of pyrogallol in THF with neither heat nor catalyst produced a mixture of products containing the complex (1), as evidenced by n.m.r. Although disproportionation of VIV under acidic conditions $\left(\mathrm{HClO}_{4}\right.$ in $\left.\mathrm{MeCN}\right)$ has been reported to give $\mathrm{VIII}$ and $\mathrm{VV}, 18$ this is not occurring here because no acid was employed. The results support the idea that the large amount of tunichrome present in $A$. nigra blood 3.4 might reduce $\mathrm{V}^{\mathrm{V}}$ to $\mathrm{VIII}$ in vivo.

This research was supported by a grant from the National Institutes of Health. R. B. F. was supported by the National Science Foundation.

\section{References}

1 (a) R. M. K. Carlson, Proc. Nat. Acad. Sci. USA, 1975, 72, 2217; (b) T. D. Tullius, W. O. Gillum, R. M. K. Carlson, and K. O. Hodgson, J. Am. Chem. Soc., 1980, 102, 5670; (c) E. Boeri and A. Ehrenberg, Arch. Biochem. Biophys., 1954, 50, 404; (d) S. Lee, K. Nakanishi, R. B. Frankel, and K. Kustin, J. Inorg. Biochem., in the press.

2 A. L. Dingley, K. Kustin, I. G. Macara, and G. C. McLeod, Biochim. Biophys. Acta, 1981, 649, 493.

3 R. C. Bruening, E. M. Oltz, J. Frukawa, K. Nakanishi, and K. Kustin, J. Am. Chem. Soc., 1985, 107, 5298; J. Nat. Prod., 1986, 49, 193.
4 E. M. Oltz, R. C. Bruening, M. J. Smith, K. Kustin, and K. Nakanishi, J. Am. Chem. Soc., in the press.

5 (a) I. G. Macara, G. C. McLeod, and K. Kustin, Biochem. J., 1979, 181, 457; (b) K. Kustin, S.-T. Liu, C. Nicolini, and D. L. Toppen, J. Am. Chem. Soc., 1974, 96, 7410.

6 P. J. Bosserman and D. T. Sawyer, Inorg. Chem., 1982, $21,1545$.

7 S. R. Cooper, Y. B. Koh, and K. N. Raymond, J. Am. Chem. Soc., 1982, 104, 5092.

8 (a) M. E. Cass, D. L. Greene, R. M. Buchanan, and C. G. Pierpont, J. Am. Chem. Soc., 1983, 105, 2680; (b) M. E. Cass, N. R. Gordon, and C. G. Pierpont, Inorg. Chem., 1986, 25, 3962.

9 J. Zelinka and M. Bartušek, Collect. Czech. Chem. Commun., 1971, 36, 2615.

10 (a) Sister M. C. White and A. Bard, J. Anal. Chem., 1966, 38, 61; (b) J. Zelinka, M. Bartušek, and A. Okáč, Collect. Czech. Chem. Commun., 1974, 39, 83.

11 S. Ya. Shnaiderman and A. M. Pleskonos, Russ. J. Inorg. Chem. (Engl. Transl.), 1971, 16, 207.

12 R. A. Rose and M. M. Jones, Inorg. Synth., 1957, 5, 113.

13 (a) J. R. Dorfman and R. H. Holm, Inorg. Chem., 1983, 22, 3179; (b) C. Elschenbroich, J. Heck, W. Maasa, E. Nun, and R. Schmidt, J. Am. Chem. Soc., 1983, 105, 2905; (c) H. Vahrenkamp, Chem. Ber., 1978, 111, 3472; (d) F. A. Cotton and M. Millar, J. Am. Chem. Soc., 1977, 99, 7886.

14 J. S. Griffith, Struct. Bonding, 1972, 10, 87.

15 D. R. Eaton, J. Am. Chem. Soc., 1965, 87, 3097.

16 F. Röhrscheid, R. E. Ernst, and R. H. Holm, Inorg. Chem., 1967, 6, 1315 .

17 D. M. Doddrell and A. K. Gregson, Chem. Phys. Lett., 1974, 29, 512.

18 J. A. Bonadies, V. L. Pecoraro, and C. J. Carrano, J. Chem. Soc., Chem. Commun., 1986, 1218; Inorg. Chem., 1987, 26, 1218. 